\title{
THYROID DISORDERS; AND CARDIOVASCULAR RISKS
}

1. MBBS, DIP- CARD (Pb), FCPS (Cardiology)

Associate Professor of Cardiology, Punjab Medical College /

Allied Hospital, Faisalabad.

2. MBBS, FCPS (Medicine), FCPS (Cardiology)

Assistant Professor of Cardiology, C.P.E Institute of Cardiology, Multan.

3. MBBS, MCPS,FCPS (Cardiology) Senior Registrar PIC, Lahore.

4. MBBS, FCPS (Cardiology)

Senior Registrar FIC, Faisalabad.

Correspondence Address:

Dr. Liaqat Ali

MBBS, DIP-CARD (Pb), FCPS

(Cardiology)

Associate Professor of Cardiology,

Punjab Medical College /

Allied Hospital, Faisalabad.

hudadr1@hotmail.com

Article received on:

05/09/2015

Accepted for publication:

21/09/2015

Received after proof reading:

12/10/2015

\section{Dr. Liaqat Ali ${ }^{1}$, Dr. Muhammad Tahir Mohy U Din ${ }^{2}$, Dr. Imtiaz Ahmed ${ }^{3}$, Dr. Rehan Riaz}

ABSTRACT... Background: Thyroid hormones have many effects on cardiovascular function, and deficiency or excess of thyroid hormones can result in cardiac dysfunction. Abnormalities of the cardiovascular system are often identified during examination of hyperthyroid and hypothyroid patients. Objective: The aim of this study was to address the effects of thyroid hormones on the cardiovascular system and the clinical relevance of the cardiovascular response to thyroid dysfunction. Study Design: Cross sectional study. Setting: The study was conducted at Allied Hospital / Punjab Medical College Faisalabad and PINUM Hospital Faisalabad. Period: October 2014 to August 2015. Materials and Methods: Total 100 patients with thyroid disease (Hypo/hyperthyroidism) were enrolled in the study. Any patient age $\geq 20$ years, that had documented history of thyroid disease (Hypothyroidism or hyperthyroidism) or on medications for thyroid disorder was recruited in this study. Results: Total 100 consecutive patients with abnormal thyroid function tests who fulfill the inclusion and exclusion criteria were enrolled in the study. Mean age was $47.9 \pm 23.20$ years. $16 \%$ were male and $84 \%$ were female. Majority of the patients $37(37 \%)$ were in age group $51-60$ years. $53 \%$ were suffering from overt hyperthyroidism and $31 \%$ were suffering from hypothyroidism. Subclinical hyperthyroidism and hypothyroidism was present in $7 \%$ and $9 \%$ patients respectively. Goiter was present in $24 \%$ patients. Atrial fibrillation was observed in 34\% hyperthyroid patients. Overall $23 \%$ were diabetics and $25 \%$ had $\mathrm{H} / \mathrm{O}$ hypertension. Dyslipidemia was present in $20 \%$ hyperthyroid and $25 \%$ hypothyroid patients. Echocardiography was performed in $19 \%$ patients. $7 \%$ patients undergone thyroid surgery. Overall $11 \%$ patients were suffering from CCF. Pulmonary hypertension was observed in $17 \%$ hyperthyroid and $35.48 \%$ hypothyroid patients. MeanFT4 in hypothyroid patients was $1.16 \pm 022 \mathrm{ng} / \mathrm{dl}$. Mean TSH was $10.92 \pm 21.09(\mu \mathrm{lU} / \mathrm{ml})$ in hypothyroid and $0.19 \pm 0.14(\mathrm{ll} / \mathrm{l} / \mathrm{ml})$ in hyperthyroid patients. Conclusions: The outcome of this study suggests that patients with untreated overt / subclinical thyroid dysfunction are at increased risk of cardiovascular complications.

Key words: Thyroid diseases, Hypothyroidism, Hyperthyroidism, Risk factors, Cardiovascular diseases

Article Citation: Ali L, Mohy U Din MT, Ahmed I, Riaz R. Thyroid disorders; and cardiovascular risks. Professional Med J 2015;22(10):1289-1297. DOI: 10.17957/ TPMJ/15.3084

\section{INTRODUCTION}

Thyroid diseases can result in a wide range of cardiovascular manifestations and complications like atrial fibrillation, cardiomyopathy, and congestive heart failure. In the United States, a significant number of peoples are unaware from their thyroid disorders but has laboratory evidence of thyroid disease, so screening for early detection of thyroid disorders is useful and important. Most of the cardiovascular complications in thyroid diseases are potentially reversible with appropriate treatment so in time diagnosis is important. ${ }^{1}$
During the last three decades, various clinical studies have shown that thyroid disorders are associated with an increased risk of cardiac events like coronary artery disease (CAD), cardiovascular disease (CVD)-related death, and all-cause mortality. Thyroid disorders can worsen old cardiac symptoms in those who already have CVD, or cause new ones. ${ }^{2}$ Underlying heart problems can be accelerated by thyroid disorders. By establishing the etiology of thyroid disorders, clinicians can be able to appropriately treat the disease and minimize the risk of cardiovascular complications. 
Hypothyroidism or hyperthyroidism are the most common thyroid disorders. In America approximately $4.6 \%$ population has hypothyroidism and $1.3 \%$ is suffering from hyperthyroidism. Graves's disease, an autoimmune disorder, is the most common cause of hyperthyroidism. Toxic multinodular goiter and toxic adenoma are other common causes of hyperthyroidism. ${ }^{1}$ Currently hyperthyroidism is the most frequently diagnosed endocrinopathy and was first described in 1980, and has become increasingly recognized with a prevalence of $2 \% .^{3}$

$35 \%-50 \%$ hyperthyroid patients have heart murmurs or gallop sounds. On X-Rays in $26 \%$ - $40 \%$ patients cardiomegaly was noted. Left ventricular posterior wall hypertrophy was most common echocardiographic finding in hyperthyroid patients and it was in approximately $72 \%$.

Atrial fibrillation or flutter was present in about $7-8 \%$ middle aged hyperthyroid persons and this risk may further increase with age, it was about $10-20 \%$ in elderly patients. Risk increases up to $20-35 \%$ in hyperthyroid patients with existing CVD like ischemic heart disease or valvular disease. ${ }^{4}$

Gerdes AM et al. ${ }^{5}$ found in his study that heart failure is mostly caused by untreated thyroid disorders and this was also proved by Galli E et al. ${ }^{6}$ Nanchen $D$ et al recently conducted a study in which he observed that in patients already having underlying heart disease there is a strong association between heart failure and persistent subclinical thyroid disorders. ${ }^{7}$

Subclinical hyperthyroidism is characterized by abnormal thyroid function tests often without any symptom and clinical sign of the disease. In subclinical hyperthyroidism cardiac dysfunction or atrial fibrillation is responsible for cardiac complications. $^{8}$

In hypothyroidism, cardiac manifestations are less dramatic than those of hyperthyroidism. 5\% to $22 \%$ hypothyroid patients show bradycardia. In hypothyroidism, atherosclerosis is a known com- plication of the hypercholesterolemia. ${ }^{9}$ It is a rare but serious complication of hypothyroidism and has been attributed to hypercholesterolemia, hypertension, and impaired endothelial function. ${ }^{10}$

Among middle-aged women, subclinical thyroid dysfunction is more common ${ }^{11}$; it is characterized by normal free thyroxine (free-T4) levels and abnormal serum thyroid-stimulating hormone (TSH) levels. Subclinical hypothyroidism prevalence varies from $5-6 \%$ among women of all ages and it increases with age, $10-17 \%$ women over 60 years of age are victim of subclinical hypothyroidism. ${ }^{12}$ Most of the patients with subclinical hypothyroidism (74-87\%) have serum TSH levels between 5 and $10 \mathrm{mIU} / \mathrm{l} .{ }^{13}$ It is still a subject of debate that subclinical hypothyroidism is a risk factor for cardiovascular disease or not.

\section{Materials and Methods}

This study was conducted at Allied Hospital / Punjab Medical College Faisalabad and PINUM Hospital Faisalabad from October 2014 to August 2015.

\section{Inclusion Criteria}

Any patient (Male or Female) age $\geq 20$ years with established diagnosis of hypo / hyperthyroidism.

\section{Exclusion Criteria}

1. Patients with advanced malignancy of any organ.

2. End stage renal or liver disease.

3. Patients with severe COPD.

4. Pregnant women.

5. Patients who have got thyroid surgery or radioactive iodine.

Total 100 consecutive patients of any gender who fulfill the inclusion and exclusion criteria were enrolled in the study. Any patient age $\geq 20$ years who have established thyroid disease (Hypothyroidism or hyperthyroidism) or newly diagnosed patient or on medications for thyroid disorder and he / she came in cardiology OPD or was admitted in cardiology ward through emergency of Allied hospital or patient came in PINUM hospital for thyroid function tests and he/ she had overt / 
subclinical thyroid disorder was recruited in the study. Informed written consent of all the patients was obtained at the start of the study.

The demographic data was collected and a detailed physical examination especially neck for goiter and relevant cardiovascular examination of all the patients was done. Symptoms regarding their referral for medical checkup were recorded. All the enrolled patients answered a specific questionnaire about sociodemographic characteristics and cardiovascular disease morbidity.

Hypertension was evaluated both as a categorical as well as continuous variable. Presence versus absence of hypertension was a categorical variable; presence of hypertension was defined as a value of $\geq 140 / 90 \mathrm{~mm} \mathrm{Hg}$ at three different settings or self-reported by the patient by his/ her previous medical record or based on hospital record or current use of antihypertensive medications and as a continuous variable (means systolic and diastolic blood pressure).

Diabetes was defined as a categorical variable as well as continuous variable. Presence versus absence of diabetes was a categorical variable; presence of diabetes was defined as fasting blood sugar level $\geq 126 \mathrm{mg} / \mathrm{dl}$ or random blood sugar level $\geq 140 \mathrm{mg} /$ dl or self-reported by the patient by his/her previous medical record or based on hospital record or current use of anti diabetic medications to treat diabetes).

Hypercholesterolemia was defined as a categorical variable (presence versus absence of hypercholesterolemia; hypercholesterolemia was defined according to ATP IV guidelines by previous record of the patient or hospital record or current use of medication to treat hypercholesterolemia).

Every patient got anthropometric measurements at the hospital using standardized techniques. Body mass index (BMI) was obtained by dividing the weight in kilograms by the square of height in meters. Waist circumference was measured at the maximum width area at the level of midway between the lowest rib margin and the iliac crest.
ECG of every patient was done at presentation and then daily in admitted patients. Record of previous investigations was noted. Echocardiography was done in patients with $\mathrm{H} / \mathrm{O}$ breathlessness or with suspected CCF or pericardial effusion. Random blood sugar level was taken at the time of checkup or admission.

Blood samples for glucose, total cholesterol, HDL cholesterol, LDL cholesterol and triglyceride levels were collected following an overnight fast of a minimum of 10 hours. The serum FT4 and TSH were also measured. To diagnose subclinical hypothyroidism a high serum TSH level and a normal free thyroxine (FT4) level were required and the patients were labeled to have overt hypothyroid when the $\mathrm{TSH}$ levels were high $(\mathrm{TSH}>10$ $\mu \mathrm{lU} / \mathrm{ml}$ ) and when the FT4 levels were low (FT4 $<0.93 \mathrm{ng} / \mathrm{dl})$. Patients with normal TSH $(0.27-$ $4.2 \mu \mathrm{lU} / \mathrm{ml})$ and FT4 (0.93-1.7) ng/dl levels were considered to be euthyroid. Subclinical hyperthyroidism was defined as a TSH level $<0.45 \mathrm{mIU} / \mathrm{l}$ and a normal free thyroxine level and subclinical hypothyroidism was defined as a TSH level $>4.0$ $\mathrm{mIU} / \mathrm{l}$ and a normal free thyroxine level (0.6-1.8 $\mathrm{ng} / \mathrm{dl})$.

\section{STATISTICAL ANALYSIS}

All the data was analyzed by SPSS (Statistical Package for Social Sciences) Version 14.0 for Windows. Categorical variables were expressed as frequencies and percentages and continue variables were presented as means ${ }^{ \pm}$SD Standard Deviation). Qualitative variables were compared using Chi sq test. 5\% level of significance was used. All tests applied were two tailed.

\section{RESULTS}

Total 100 patients were recruited in the study. $16(16 \%)$ were male and 84 (84\%) were female. Mean age was $47.9 \pm$ 23.20. Maximum patients (37\%) were in age group 51-60 years. Only 5\% patients were above 70 years of age (Fig-l). 53\% patients were suffering from overt hyperthyroidism and $31 \%$ were with overt hypothyroidism. 15 $\%$ patients present in emergency and $85 \%$ patients came in OPD. Overall diabetes was present in $23 \%$ and $25 \%$ were hypertensive. 


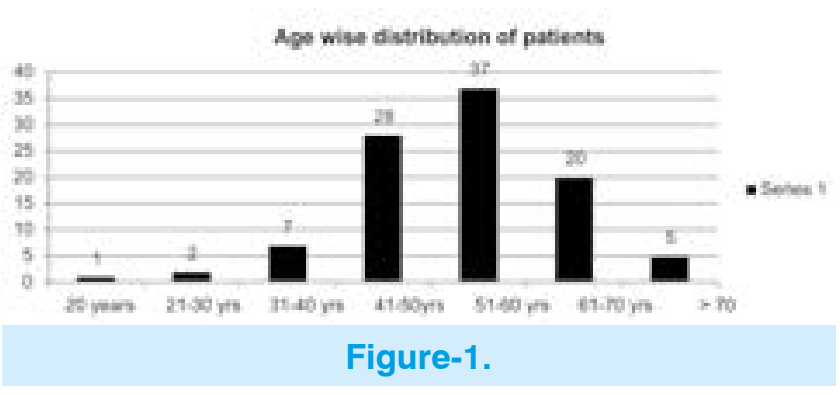

Subclinical hypothyroidism was observed in $9 \%$ patients and $7 \%$ were subclinical hyperthyroid patients. Goiter was present in $24 \%$ patients. Echocardiography was done in $19 \%$ patients (Table I). Regarding cardiac manifestations, 42(79.24\%) hyperthyroid patients present with palpitation. $34 \%$ hyperthyroid patients had atrial fibrillation. Pulmonary hypertension was observed in $20 \%$ patients overall, 9 were hypothyroid and 11 were hyperthyroid (Table II). 25(47.16\%) hyperthyroid patients present with chest pain. CCF was present in $11(11 \%)$ patients. $18 \%$ patients came in life threatening condition, 15 were hyperthyroid and 03 were hypothyroid patients (Table II). Overall history of dyslipidemia was present in $23 \%$. Mean systolic blood pressure in hyperthyroid patients was $135 \pm 13.40 \mathrm{mmHg}$ and it was $123 \pm 8.2$ $\mathrm{mmHg}$ in hypothyroid patients. FT4 and TSH was $1.16 \pm 0.22 \mathrm{ng} / \mathrm{dl}$ and $10.92 \pm 21.09(\mathrm{ulU} / \mathrm{ml})$ respectively in subclinical hypothyroid patients. Total cholesterol was $206 \pm 46.4 \mathrm{mg} / \mathrm{dl}$ in hyperthyroid patients and was $204 \pm 46 \mathrm{mg} / \mathrm{dl}$ in hypothyroid patients (Table III).

\section{DISCUSSION}

Abnormalities of the cardiovascular system are often identified during examination of hyperthyroid and hypothyroid patients. During the last three decades, numerous clinical studies have shown that thyroid diseases are associated with an increased risk for manifestations of coronary artery disease (CAD) as well as higher rates of cardiac events, cardiovascular disease (CVD)-related death, and all-cause mortality. Those patients who already have existing CVD, disorders of the thyroid gland can worsen old cardiac symptoms or cause new ones.

\begin{tabular}{|c|c|c|}
\hline Characteristics & Frequency & $\%$ age \\
\hline $\begin{array}{l}20 \text { Years } \\
21-30 \text { Years } \\
31-40 \text { Years } \\
40-50 \text { Years } \\
50-60 \text { Years } \\
60-70 \text { Years } \\
.>70 \text { Years }\end{array}$ & $\begin{array}{c}1 \\
2 \\
07 \\
28 \\
37 \\
20 \\
05\end{array}$ & \begin{tabular}{l|}
$1 \%$ \\
$2 \%$ \\
$07 \%$ \\
$28 \%$ \\
$37 \%$ \\
$20 \%$ \\
$05 \%$
\end{tabular} \\
\hline $\begin{array}{l}\text { Male } \\
\text { Female }\end{array}$ & $\begin{array}{l}16 \\
84\end{array}$ & $\begin{array}{l}16 \% \\
84 \%\end{array}$ \\
\hline Goiter & 24 & $24 \%$ \\
\hline Hyperthyroidism & 53 & $53 \%$ \\
\hline Hypothyroidism & 31 & $31 \%$ \\
\hline Subclinical Hyperthyroidism & 07 & $07 \%$ \\
\hline Subclinical Hypothyroidism & 09 & $09 \%$ \\
\hline Diabetes Mellitus & 23 & $23 \%$ \\
\hline Hypertension & 25 & $25 \%$ \\
\hline Tremor & 43 & $43 \%$ \\
\hline Obesity & 23 & $23 \%$ \\
\hline $\begin{array}{l}\text { Pts on Treatment } \\
\text { On Thyroxin } \\
\text { On Neomercazole }\end{array}$ & $\begin{array}{l}26 \\
48\end{array}$ & $\begin{array}{l}26 \% \\
48 \%\end{array}$ \\
\hline $\begin{array}{l}\text { Mode of Presentation } \\
\text { Emergency } \\
\text { OPD }\end{array}$ & $\begin{array}{l}15 \\
85\end{array}$ & $\begin{array}{l}15 \% \\
85 \% \\
\end{array}$ \\
\hline Echo done & 19 & $19 \%$ \\
\hline Thyroid Antibodies +ve & 09 & $09 \%$ \\
\hline Thyroid Surgery done & 07 & $07 \%$ \\
\hline Patients need admission & 13 & $13 \%$ \\
\hline Difficulty in Swallow & 05 & $05 \%$ \\
\hline
\end{tabular}

In our study the patients in the 50-60 years age group had a higher prevalence of thyroid dysfunction as compared to the other age groups and these were comparable with the results of Rotterdam's study ${ }^{14}$ in which he observed $10.8 \%$ prevalence of subclinical hypothyroidism among elderly women. There were $84 \%$ female and $16 \%$ male patients in our study and it is evident from other international studies that the thyroid disease is much more prevalent in women than in men.

Atrial fibrillation is the most common complication of hyperthyroidism and it is observed in approx- 


\begin{tabular}{|c|c|c|c|c|}
\hline Cardiac Manifestations & $\begin{array}{l}\text { Hyperthyroidism } \\
\quad(n=53)\end{array}$ & $\begin{array}{l}\text { Hypothyroidism } \\
\quad(n=31)\end{array}$ & $\begin{array}{c}\text { Subclinical } \\
\text { Hyperthyroidism } \\
(\mathrm{n}=07)\end{array}$ & $\begin{array}{c}\text { Subclinical } \\
\text { Hypothyroidism } \\
(\mathrm{n}=09)\end{array}$ \\
\hline Palpitation & $42(79.24 \%)$ & $02(6.45 \%)$ & $02(28.6 \%)$ & $01(11.11 \%)$ \\
\hline A. Fibrillation & $18(34 \%)$ & $01(3.22 \%)$ & $01(14.3 \%)$ & Nil \\
\hline Pul. Hypertension & 09 (17\%) & $11(35.48 \%)$ & Nil & Nil \\
\hline CKD & 03 (5.7\%) & $02(6.45 \%)$ & Nil & Nil \\
\hline Diabetes Mellitus & $12(22.64 \%)$ & $09(29 \%)$ & $01(14.3 \%)$ & $01(11.11 \%)$ \\
\hline Chest Pain & $25(47.16 \%)$ & 03 (9.7\%) & $01(14.3 \%)$ & Nil \\
\hline ACS & $09(17.1 \%)$ & $02(6.45 \%)$ & Nil & Nil \\
\hline CCF & $06(11.32 \%)$ & 03 (9.71\%) & $01(14.3 \%)$ & $01(11.11 \%)$ \\
\hline Bradycardia & Nil & $14(45.16 \%)$ & Nil & $02(22.22 \%)$ \\
\hline Dyspnoea & 15 (28.30\%) & $11(35.5 \%)$ & $02(28.6 \%)$ & 02 (22.22\%) \\
\hline Life threatening condition & $15(28.30 \%)$ & 03 (9.7\%) & Nil & Nil \\
\hline Hypertension & $17(32 \%)$ & 06 (19.35\%) & $01(14.3 \%)$ & 01 (11.11\%) \\
\hline
\end{tabular}

\begin{tabular}{|c|c|c|}
\hline Characteristics and CV Risk Factors & $\begin{array}{c}\text { Hypothyroidism }(n=40) \\
\text { ( Overt + Subclinical) }\end{array}$ & $\begin{array}{l}\text { Hyperthyroidism }(n=60) \\
\text { ( Overt + Subclinical) }\end{array}$ \\
\hline Age (years) ${ }^{*}$ & $50 \pm 5$ & $47 \pm 4.3$ \\
\hline Smoking \% & $07(17.5 \%)$ & $07(11.7 \%)$ \\
\hline Sedentary life \% & $17(42.5 \%)$ & $31(51.7 \%)$ \\
\hline Angina $\%$ & $05(12.5 \%)$ & $15(25 \%)$ \\
\hline Waist Circumference $(\mathrm{cm}){ }^{*}$ & $92.8 \pm 19.1$ & $80 \pm 11.8$ \\
\hline Body Mass Index ( kg/m2) * & $28 \pm 6$ & $26 \pm 4$ \\
\hline Presence of Hypertension \% & $9(22.5 \%)$ & $16(26.7 \%)$ \\
\hline Presence of Dyslipidemia\% & $08(20 \%)$ & $15(25 \%)$ \\
\hline Presence of Diabetes \% & $07(17.5 \%)$ & $16(26.7 \%)$ \\
\hline Systolic Blood pressure $(\mathrm{mmHg}){ }^{*}$ & $135 \pm 13.4$ & $123 \pm 18.2$ \\
\hline Diastolic Blood pressure $(\mathrm{mmHg})^{*}$ & $87 \pm 9.2$ & $81.4 \pm 11$ \\
\hline Fasting Blood Sugar ( mg/dl) * & $133 \pm 45.9$ & $88 \pm 8.2$ \\
\hline Total Cholesterol $(\mathrm{mg} / \mathrm{dl}){ }^{*}$ & $206 \pm 46.4$ & $204 \pm 46$ \\
\hline $\mathrm{HDL}-\mathrm{C}(\mathrm{mg} / \mathrm{dl}){ }^{*}$ & $54 \pm 12.8$ & $56 \pm 13.1$ \\
\hline LDL- C (mg/dl) * & $126.2 \pm 33.6$ & $118 \pm 45$ \\
\hline
\end{tabular}

\begin{tabular}{|l|c|c|}
\hline \multicolumn{1}{|c|}{ Characteristics } & $\begin{array}{c}\text { Subclinical Hypothyroidism } \\
\mathbf{n = 0 9}(\mathbf{1 0 0 \% )}\end{array}$ & $\begin{array}{c}\text { Subclinical Hyperthyroidism } \\
\mathbf{n = 0 7}(\mathbf{1 0 0 \% )}\end{array}$ \\
\hline FT4 (ng/dl) ${ }^{*}$ & $1.16 \pm 0.22 \mathrm{~b}$ & $1.2 \pm 0.3$ \\
\hline TSH (mU/ L) * & $10.92 \pm 21.09$ & $0.19 \pm 0.14$ \\
\hline Presence of TPO-AB & $4(44.4 \%)$ & $3(42.8 \%)$ \\
\hline \multicolumn{2}{|c|}{ Table-IV. Thyroid stimulating hormone (TSH), free-T4 levels in patients with subclinical thyroid disease } \\
\end{tabular}


imately $15 \%$ patients. Middle aged hyperthyroid patients have risk of atrial fibrillation and/ or flutter about $7-8 \%$ and this risk may further increase with age and it is up to $10-20 \%$ in elderly patients. Those patients who already are cardiac patients and suffering from IHD or valvular heart disease have risk of atrial fibrillation up to $20-35 \% .{ }^{6}$ It is more common in old male patients and prevalence is about $25 \%$ to $40 \%$ in $\geq 60$ years of age. Risk of atrial fibrillation is $>3$ times in subclinical hyperthyroidism. ${ }^{15}$ In our study, atrial fibrillation was observed overall in $20 \%$ patients and these results are comparable with the other studies.

Hypertension is a common complication of hyperthyroidism, and its prevalence varies from $10 \%$ to $20 \%$ depending on the population enrolled in the study. ${ }^{16}$ Our results revealed that overall $25 \%$ patients with thyroid dysfunction had history of hypertension and its prevalence was 32\% in hyperthyroid patients and these results are consistent with other studies.

Pulmonary hypertension and hyperthyroidism has strong association with each other, hyperthyroid patients may develop right ventricular failure due to pulmonary hypertension ${ }^{17}$ and in the study $17 \%$ hyperthyroid patients had pulmonary hypertension on echocardiography. In many prospective studies, prevalence of pulmonary arterial hypertension was $40 \%$ to $94 \%$ in patients with autoimmune thyroid disease ${ }^{4}$ and it is usually reversible when the patient become euthyroid so pulmonary arterial hypertension may be underestimated in hyperthyroidism.

In the study $11 \%$ patients were found to have CCF and these results were comparable with other international studies. Siu et all conducted a cohort study on 591 consecutive hyperthyroid patients and he found that HF was present in $6 \%$ patients. ${ }^{18}$ Recently in the Prospective Study of Pravastatin in the Elderly at Risk (PROSPER) it was observed that old patients with subclinical hyperthyroidism and existing cardiac diseases are more at risk to develop $\mathrm{HF}^{7}$ and in this study it was also observed that even a mild increase in thyroid hormone can increase risk of heart failure in older age especially $>70$ years. ${ }^{7}$ Recently six prospective studies were conducted on 2068 patients, it was confirmed that patients with subclinical hypothyroidism are at increased risk of HF. ${ }^{19}$ In patients with a TSH level $>10 \mathrm{mU} / \mathrm{l}$, there was a statistically significant increased risk to develop $\mathrm{HF}$ as compared with persons having normal TSH values. ${ }^{20}$ In 2008 a Cardiovascular Health Study was conducted on 3065 patients, in which echocardiography were performed over 6 years of follow-up in subjects aged $\geq 65$ years to identify the risk of $\mathrm{HF}^{20}$ in which it was observed that there is higher peak $\mathrm{E}$ velocity in individuals with $\mathrm{TSH}$ levels $\geq 10 \mathrm{mU} / \mathrm{l}$. In patients with chronic heart failure, subclinical hypothyroidism is a risk factor for cardiac death, confirmed by many studies. ${ }^{21}$

Decreased glomerular filtration, impaired free water clearance and hyponatremia were noted in hypothyroidism due to decreased renal perfusion..$^{22}$ In patients with impaired renal function and thyroid disorder sub clinical hypothyroidism was present in $53 \%$ and overt hypothyroidism was present in $25 \%$ patients. In our study overall $5 \%$ patients had history of CKD and these results are consistent with other studies.

Recently Rohit R Arora ${ }^{1}$ and colleagues followed patients from 4 to 20 years in meta- analysis studies and they found that subclinical hypothyroidism was associated with a significant risk of CHD. $\mathrm{He}$ also observed that mortality due to cardiovascular causes was significantly higher in patients with subclinical hyperthyroidism. Arora said that subclinical thyroid disorders often remain masked and undiagnosed, so it's important to increase awareness among clinicians. In subclinical hypothyroidism cardiovascular events are most probably due to cardiac dysfunction, atherosclerotic disease or hypercholestremia. ${ }^{23}$ In patients with subclinical hypothyroidism particularly with TSH $>10 \mathrm{mU} / \mathrm{l}$ an increased risk of CAD events and mortality has been reported in young patients.

Hypercholesteremia has been observed in overt hypothyroidism. In diabetics, dyslipidemia may be due to complex interplay between thyroid function and insulin resistance. ${ }^{24}$ Hyperlipid- 
emia, insulin resistance, hypercoagulability and low grade inflammation has been observed in sub-clinical hypothyroidism ( $\mathrm{SCH}$ ) and overt hypothyroidism $(\mathrm{OH})$. Dyslipidemia and hypothyroidism has strong association and in our study dyslipidemia was present in $20 \%$ hypothyroid and $25 \%$ hyperthyroid patients. Studies have proved that prevalence of hyperlipidemia in overtly hypothyroid patients is up to $90 \%$. Increased level of total cholesterol, low-density lipoprotein (LDL) cholesterol, apolipoprotein B, lipoprotein (a) $[\mathrm{Lp}(\mathrm{a})]$ and possibly, triglyceride have been observed in overt hypothyroidism. ${ }^{25}$ The prevalence of hypothyroidism (subclinical and overt) is more common as compared to hyperthyroidism so early detection and thyroxine replacement could reduce the significant cardiovascular risks in hypothyroidism. However, still it is not proven that thyroxine replacement in subclinical hypothyroidism would be beneficial or not.

Some studies have proved that there is an association between cardiovascular diseases and subclinical hypothyroidism or hyperthyroidism but other studies did not show any association. ${ }^{26}$ Even though, recent systematic review on subclinical thyroid disease confirmed the association between CVD events and thyroid disorders but most scientific/medical societies do not recommend screening for thyroid disease among general populations.

hsCRP is a novel, non-classic cardiovascular risk factor and some studies have found its association with subclinical thyroid disease. ${ }^{27}$ There are conflicting results regarding hsCRP: three studies showed some correlation with thyroid disorders , while another three did not show any association at all. ${ }^{28}$

\section{CONCLUSIONS}

The outcome of this study is that patients with untreated overt/ subclinical thyroid dysfunctions are at increased risk of cardiovascular complications. Both hypothyroidism and hyperthyroidism can cause cardiovascular diseases and when the thyroid dysfunction is treated and controlled most of the cardiovascular changes are reversible but severely affected patients may need specific treatment. Early and timely diagnosis of thyroid disorders and recognition of cardiac complications is important because most of the cardiac manifestations are reversible with treatment and prognosis depends on early treatment of thyroid dysfunction. Cooperation between endocrinologists and cardiologists is essential to improve the prognosis of severe cardiac complications in overt / subclinical thyroid dysfunction.

\section{STUDY LIMITATIONS}

The present study has several limitations. The study sample was not a population-based sample however; this was a sample in which a possible association between thyroid disease and cardiovascular risk factors could easily be demonstrated. The results have implications for clinical practice.

\section{FUTURE RECOMMENDATION}

This is just a preliminary report regarding cardiovascular risks and complications in thyroid dysfunction and future studies with a larger sample size may be considered.

\section{Copyright $@ 21$ Sep, 2015.}

\section{REFERENCES}

1. Rohit $\mathrm{R}$ Arora. Addressing Cardiovascular Risks in Thyroid Disorders. PHYSICIANS WEEKLY 6 ${ }^{\text {th }}$ Sep.2012.

2. Jodi K. Sangster, DVM, David L. Panciera, DVM, MS, DACVIM (Small Animal Internal Medicine), Jonathan A. Abbott, DVM, DACVIM (Cardiology). Compendium July 2013(Vol 35, No 7).

3. Edinboro $\mathrm{CH}$, Scott- Moncrieff JC, Janovitz $\mathrm{E}$ et al. Epidemiology study of relationships between consumtion of commercial canned food and risk of hyperthyroidism in cats: $\mathrm{J} \mathrm{Am}$ Vet Med Assoc 2004; 224:879-886.

4. Biondi B \& Kahaly GJ. Cardiovascular involvement in patients with different causes of hyperthyroidism. Nature Reviews. Endocrinology 2010; 6 431-443.

5. Gerdes AM \& lervasi G. Thyroid replacement therapy and heart failure. Circulation 2010; 122 385-393.

6. Galli $E$, Pingitore A \& lervasi $G$. The role of thyroid hormone in the pathophysiology of heart failure: clinical evidence. Heart Failure Reviews 2010; 15 155169. 
7. Nanchen D, Gussekloo J, Westendorp RG, Stott DJ, Jukema JW, Trompet S, Ford I, Welsh P, Sattar N, Macfarlane PW, Mooijaart SP, Rodondi N, de Craen AJ \& PROSPER Group. European Journal of Endocrinology (2012) 167.

8. Biondi B, Palmieri EA, Lombardi G, Fazio S. Effects of subclinical thyroid dysfunction on the heart. Ann Intern Med. 2002; 137(11):904-14.

9. Fazio, S, Palmieri EA, Lombardi G, et al. Effects of thyroid hormone on the cardiovascular system. Recent Prog Horn Res 2004; 59:31-50.

10. Ichiki T. Thyroid hormone and atherosclerosis. Vasc Pharmocol 2010; 52:151-156.

11. Canaris GJ, Manowitz NR, Mayor G, Ridgway EC. The Colorado thyroid disease prevalence study. Arch Intern Med. 2000; 160(4):526-34.

12. Díez JJ, Iglesias P. Spontaneous subclinical hypothyroidism in patients older than 55 years: an analysis of natural course and risk factors for the development of overt thyroid failure. J Clin Endocrinol Metab. 2004; 89(10):4890-7.

13. Vanderpump M. Subclinical hypothyroidism: the case against treatment. Trends Endocrinol Metab. 2003; 14(6):262-6.

14. Elisabeth H A, Huibert AP P, Visser JT, Drexhage HA, Hofman A and Jacqueline CV W. Subclinical Hypothyroidism Is an Independent Risk Factor for Atherosclerosis and Myocardial Infarction in Elderly Women: The Rotterdam Study. Annals of Internal Medicine, 2000; 132(4):270-278.

15. Sawin CT, Andrew G, Philip AW, Albert J B, Errol B, Pamela B, Peter W, Emelia JB and Ralph BD. Low Serum Thyrotropin Concentrations as a Risk Factor for Atrial Fibrillation in Older Persons. N Engl J Med ,1994; 31:1249- 1252.

16. Williams TL, Peak KJ, Brodbelt $D$ et al. Survival and the development of zotemia after treatment of hyperthyroid cats. J Vet Intern Med 2010; 24:863-869.

17. Ismail HM. Reversible pulmonary hypertension and isolated right-sided heart failure associated with hyperthyroidism. Journal of General Internal Medicine 2007; 22 148-150.

18. Siu CW, Yeung CY, Lau CP, Kung AW \& Tse HF. Incidence, clinical characteristics and outcome of congestive heart failure as the initial presentation in patients with primary hyperthyroidism. Heart 2007; 93 483-487.
19. Gencer B, Collet TH, Virgini V, Bauer DC, Gussekloo J, Cappola AR, Nanchen D, den Elzen WPJ, Balmer P, Luben RN, lacoviello M, Triggiani V, Cornuz J, Newman $A B$, Khaw KT, Jukema JW, Westendorp RGJ, Vittinghoff E, Aujesky D, Rodondi N \& Thyroid Studies Collaboration. Subclinical thyroid dysfunction and the risk of heart failure events: an individual participant data analysis from six prospective cohorts. Circulation 2012; 126 1040-1049.

20. Rodondi N, Bauer DC, Cappola AR, Cornuz J, Robbins $J$, Fried LP, Ladenson PW, Vittinghoff E, Gottdiener JS \& Newman $A B$. Subclinical thyroid dysfunction, cardiac function, and the risk of heart failure. The Cardiovascular Health Study. Journal of the American College of Cardiology 2008; 52 1152-1159.

21. Silva-Tinoco $R$, Castillo-Martı 'nez $L$, Orea-Tejeda $A$, Orozco-Gutie 'rez JJ, Va`zquez-DA az O, Montano'Herna'ndez P \& Flores-Rebollar A. Developing thyroid disorders is associated with poor prognosis factors in patient with stable chronic heart failure. International Journal of Cardiology 2011; 147 e24-e25.

22. Fazio S, Palmieri EA, Lombardi G \& Biondi B. Effects of thyroid hormone on the cardiovascular system. Recent Progress in Hormone Research 2004; 59 31-50.

23. Singh BM, Goswami B and Mallika V. Association between insulin resistance and hypothyroidism in females attending a tertiary care hospital. Indian Journal of Clinical Biochemistry, 2010; 25 (2) 141-145.

24. Meier C, Staub JJ, Roth CB, et al. TSH-controlled L-thyroxine therapy reduces cholesterol levels and clinical symptoms in subclinical hypothyroidism: a double blind, placebo-controlled trial (Basel Thyroid Study). J Clin Endocrinol Metab. 2001; 86(10):4860-6.

25. Elizabeth NP. Hypothyroidism and dyslipidemia: Modern concepts and approaches. Current Cardiology Reports, 2004; 6(6), 451-456.

26. Gussekloo J, van Exel E, de Craen AJ, Meinders AE, Frölich M, Westendorp RG. Thyroid status, disability and cognitive function, and survival in old age. JAMA. 2004; 292(21):2591-9.

27. Jublanc C, Bruckert E, Giral P, et al. Relationship of circulating C-reactive protein levels to thyroid status and cardiovascular risk in hyperlipidemic euthyroid subjects: low free thyroxine is associated with elevated hsCRP. Atherosclerosis. 2004; 172(1):7-11.

28. Hueston WJ, King DE, Geesey ME. Serum biomarkers for cardiovascular inflammation in subclinical hypothyroidism. Clin Endocrinol (Oxf). 2005; 63(5):5827. 


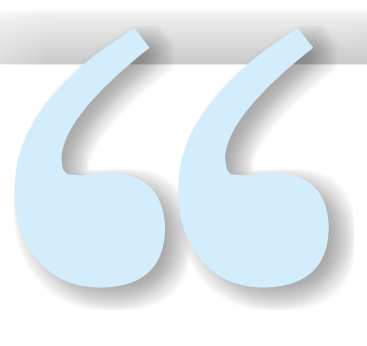

\title{
"Winners never quit and Quitters never win."
}

\author{
Vince Lombardi
}

\begin{tabular}{|c|l|l|l|}
\hline \multicolumn{3}{|c|}{ AUTHORSHIP AND CONTRIBUTION DECLARATION } \\
\hline Sr. \# & \multicolumn{1}{|c|}{ Author-s Full Name } & \multicolumn{1}{|c|}{ Contribution to the paper } & Author=s Signature \\
\hline 1 & Dr. Liaqat Ali & Data Collection \\
2 & Dr. M. Tahir Mohy U Din & Writing \\
3 & Dr. Imtiaz Ahmed & Writing & \\
4 & Dr. Rehan Riaz & Statistical Analysis \\
\hline
\end{tabular}

